\title{
QUESTÕES DE GÊNERO E JUSTIÇA SOCIAL ${ }^{1}$ \\ QUESTIONS OF GENDER AND SOCIAL JUSTICE
}

Raewyn Connell ${ }^{2}$

RESUMO: Questões de identidade e métodos desconstrucionistas têm caracterizado a teoria de gênero no Norte global nas últimas décadas. Mas as questões chave acerca do gênero no Sul global são de cunho social, o que requer uma abordagem diferenciada para que se possa compreendê-lo. As teorias sociais do gênero e da justiça atualmente reconhecem as múltiplas dimensões das questões de gênero, tais como organização, violência, reconhecimento e os problemas de inclusão. Levamos as questões de mudança, multiplicidade (por exemplo, de Masculinidades) e as diferentes ordens de gênero em todo o mundo para além de dicotomias. Como evidenciou o trabalho pioneiro de Heleieth Saffioti, a análise de gênero lida com estruturas de grande escala. A economia do conhecimento dominante privilegia as teorias advindas do Norte global. Mas cada vez mais reconhecemos a colonialidade do gênero e a análise de gênero que emerge de um mundo majoritariamente pós-colonial. Isto inclui diferentes abordagens para a identidade, o poder e o Estado, além de novas temáticas, como a relação entre o gênero e o direito a terra. Para tanto, no desenvolvimento das perspectivas de gênero necessárias para alcançar uma concepção em escala mundial, as relações $\mathrm{Sul} / \mathrm{Sul}$ serão vitais.

Palavras-chave: gênero; justiça social; conhecimento; colonialidade; feminismo; teoria.

\footnotetext{
${ }^{1}$ Tradução de Enéias Farias Tavares e Andrio Santos.

${ }^{2} \mathrm{PhD}$. em Ciëncias Sociais e Professora Emérita da Universidade de Sidney, Sidney, NSW, Austrália; E-mail: raewyn.connell@sydney.edu.au
} 
ABSTRACT: Questions of identity, and deconstructionist methods, have characterised gender theory in the global North in recent decades. But the key issues about gender in the global South are social issues, which require a different approach to understanding gender. Social theories of gender and justice now recognize the multiple dimensions of gender issues, such as organization, violence, recognition and problems of embodiment. We move beyond dichotomies to questions of change, multiplicity (e.g. of masculinities) and the different gender orders across the world. As the pioneering work of Heleieth Saffioti showed, gender analysis deals with large-scale structures. The dominant economy of knowledge privileges theory from the global North. But increasingly we recognize the coloniality of gender and the gender analysis that come from the post-colonial majority world. This includes different approaches to identity, to power and the state, and new thematics such as the relation between gender and the land. In developing the gender perspectives that are needed for the pursuit of gender on a world scale, South/South relations will be vital.

Keywords: gender; social justice; knowledge; coloniality; feminism; theory.

\section{INTRODUÇÃO}

Este artigo é uma reflexão sobre a dimensão do gênero na sociedade e sobre a dimensão social no gênero. Esta não é atualmente uma preocupação influente, seja na política convencional ou em estudos de gênero nas universidades. Hoje em dia o quadro mais influente para as políticas públicas a nível mundial é o neoliberalismo, seja aplicado de forma mais flexível ou mais enfática. $\mathrm{O}$ pensamento neoliberal não tem lugar para o gênero além de garantias vagas, de que a igualdade de oportunidade no mercado irá resolver todos os problemas relativos à questão. Se o neoliberalismo tem qualquer teoria social, esta é baseada na economia de mercado, que simplesmente exclui temas como o gênero de seu quadro de interesse.

Nos estudos de gênero, a mais influente teórica feminista atual- 
mente é uma filósofa desconstrucionista, sendo que as gerações recentes de estudantes foram impulsionadas pela teoria queer, análise do discurso e os estudos culturais. Um conjunto de questões sobre identidade, sua implantação, suas complexidades e sua fragilidade, tem sido fundamental para os estudos de gênero em caráter internacional nas últimas duas décadas. Tais preocupações dão pouca atenção à justiça social.

As questões de identidade e os estudos em torno delas são distintamente produtos do Norte global. Sua problemática reflete a situação cultural, política e econômica da metrópole mundial - isto é, os ricos, de capital-intensivo e militarmente poderosos países da região do Atlântico Norte. A teoria de gênero, como a conhecemos atualmente, advém principalmente do Norte (Ver Connell, 2006).

A partir da perspectiva do Sul global, o mundo parece diferente e os problemas relevantes são diferentes. Consideremos, por exemplo, os Objetivos de Desenvolvimento para o Milênio adotados pelas Nações Unidas - que deveriam ser alcançados no próximo ano, 2015. Os Objetivos incluem questões de gênero, mas não se tratam de questões sobre identidade. Tais metas são sobre educação, saúde, assistência médica, desigualdade econômica e poder. De fato: problemas sociais. Podemos acrescentar a violência de gênero como um problema massivo em grande parte do Sul global. É a partir da análise social de gênero que temos que abordar essas questões, sendo que às ciências sociais cabe fornecer uma base de conhecimento relevante.

Neste artigo, discuto três problemas conceituais, medidas necessárias para uma abordagem adequada envolvendo questões de prática política. Em primeiro lugar, o modo como poderíamos refletir sobre a justiça em questões de gênero; em segundo, o tipo de teoria de gênero que precisamos; e em terceiro, a importância de perspectivas Sul-globais na análise de gênero.

\section{JUSTIÇA E INJUSTIÇA NAS RELAÇÕES DE GÊNERO}

Discussões Anglófonas clássicas do conceito de justiça têm pouco a dizer a respeito do gênero. Este não é um problema abordado em Uma Teoria da Justiça (1971), de John Rawls; em fato, pode-se 
dizer que o gênero foi sistematicamente dissimulado, enquanto o sujeito modelo de justiça distributiva de Rawls é verdadeiramente um chefe de família. Da mesma forma, na abordagem Marxista de David Harvey em Justiça Social e a Cidade (1973), a preocupação com classes sobrepuja todas as outras relações sociais. Harvey discute a relação entre "homem e natureza", mas não a relação entre homem e mulher. O Esféras da Justiça (1983), de Michael Walzer, estabelece um modelo de igualdade complexa, que reconhece a "questão da mulher". Todavia, esta é abordada de forma marginal pelo autor, que a trata em apenas três páginas no final de seu livro.

Essas discussões não se aprimoraram antes que a crítica feminista a tais modelos tomasse forma e a dimensão social da opressão das mulheres se tornasse uma questão fundamental. O tratamento dado por Iris Marion Young à opressão, como um conceito estrutural, em seu livro Justiça e Política da Diferença (1990), marca a mudança. Uma vez que o gênero é entendido como uma estrutura de relações sociais, o pensamento feminista é uma reivindicação por justiça social.

"Justiça" é, em primeira instância, uma reivindicação de reparação. A justiça social é uma reivindicação de reparação da desigualdade, que acaba por trazer tanto vantagens quanto desvantagens enquanto características institucionalizadas da vida social.

Tais vantagens e desvantagens nas relações de gênero assumem múltiplas formas. Essa é uma lição realmente importante advinda da pesquisa em ciências sociais e, neste aspecto, as concepções de análise de gênero atuais avançaram decisivamente para além dos modelos unidimensionais de patriarcado, correntes há trinta anos.

Uma dimensão vital é a desigualdade material, incluindo o controle da riqueza e do acesso à renda e à habitação. $\mathrm{O}$ "dividendo patriarcal”, ganho coletivo dos homens a partir de uma ordem de gênero desigual (Connell, 2003), é um fato material que extrapola as diferenças salariais. Diz respeito também às diferenças nas taxas de participação econômica, acumulação de riqueza, propriedade de veículos, edifícios e outros ativos. É importante, no entanto, reconhecer que os homens não compartilham de forma igualitária do dividendo patriarcal. Divisões de classe, privilégio de raça e exclusão, diferen- 
ças rurais/urbanas, além de outras forças, produzem hierarquias de riqueza e pobreza. Como Kopano Ratele (2013) enfaticamente observou, os homens na base de tais hierarquias, como jovens negros na África do Sul, têm muito a temer, e sofrem excessiva violência.

Uma vez que a economia global neoliberal centra-se na produção e comércio em larga escala (embora a maioria dos trabalhadores, na verdade, trabalhe em empresas de pequena escala), o acesso ao poder organizacional torna-se um fator crucial da produção de desigualdades. Qualquer um que veja tentado a compreender nossa era como pós-feminista necessita apenas direcionar seu olhar para o monopólio virtual de gênero nos principais cargos de gestão em empresas transnacionais, assim como para a elaboração de políticas econômicas no estado neoliberal. Pesquisas recentes sobre gestão em corporações transnacionais documentaram a cultura fortemente masculina que envolve a tomada de decisões nos negócios, além da relação entre os gestores e as forças de trabalho divididas por gênero nos países onde estes realizam suas operações (Elias, 2008; Olavarría, 2009).

No entanto, padrões culturais são uma importante fração do significado da justiça de gênero. Onde reina o sexismo, onde a difamação do feminino ou da mulher é endêmica, a injustiça está presente, resultando ou não em desigualdades materiais. O reconhecimento de igualdade é negado. Este é um tema das críticas feministas nortenhas acerca de conceitos de justiça, elaborados por filósofas como Iris Young e Nancy Fraser, cujas preocupações são amplamente compartilhadas por pesquisadores e ativistas.

A justiça como reconhecimento é uma questão particularmente importante para mulheres transexuais. É também um assunto difícil de ser abordado, porque o reconhecimento destes indivíduos é frequentemente negado pelo Estado, assim como pelos seus serviços de segurança e saúde. Por vezes, um reconhecimento perverso se manifesta na forma de construções sociais hostis que legitimam a exclusão, numa forma de violência pessoal ou institucional (Namaste, 2011). A discussão de Mario Felipe de Lima Carvalho (2011) sobre a ideia de "impureza" atribuída a travestis e transexuais é relevante neste ponto. As autobiografias de mulheres e homens transexuais na 
África do Sul mostram a profunda importância do reconhecimento de gênero pelas famílias e comunidades, assim como por órgãos estatais (Morgan; Marais e Wellbeloved, 2009). Ainda, não podemos negligenciar os fatos brutos acerca da pobreza e da exclusão econômica na formação de vidas transexuais. O corrente estudo de Natatxa Carreras Sendra (2009) sobre as vidas das "vestidas", travestis profissionais do sexo no México, deixa isso claro. Conforme dito por um deles: "viejo, puto y feo, preferible muerto".

A violência também é um grande problema envolvendo a justiça de gênero, problema que não se encaixa facilmente nas categorias "material" ou de "reconhecimento" - embora esteja ligada a ambos. A violência é uma prática de inclusão social, numa ação que ou destrói ou danifica corpos. Tais práticas são estruturadas socialmente e em grande medida são geradas pela própria dinâmica social. Uma verdade que se aplica às práticas rotineiras, antes socialmente invisíveis, de violência doméstica e abuso sexual dentro da família, como Heleieth Saffioti (2004) deixa claro. São igualmente verdadeiras as impressionantes concentrações de violência baseada no gênero, como os feminicídios de Ciudad Juárez (Cruz, 2013), ou a Partilha da violência na Índia, envolvendo estupros em massa e sequestros de mulheres hindus ou muçulmanas, analisados por Veena Das (1995).

A violência integra, portanto, uma arena que compõe o conflito de justiça e injustiça no âmbito da inclusão social. Esta arena também inclui a questão da prática sexual, sobretudo quando levamos em conta as consequências à jusante, tais como os padrões sociais de infecção pelo HIV e AIDS (Epstein; Morrell; Moletsane e Unterhalter, 2004). A justiça social se tornou uma questão central envolvendo o tratamento antiretroviral para a AIDS - que foi originalmente negado aos pobres pelas estratégias de lucro homicidas das empresas farmacêuticas. A justiça em caráter de inclusão social inclui nutrição. Esta é uma questão de gênero devido à divisão das tarefas domésticas baseadas no caráter sexual (quantos maridos costumam cozinhar?), assim como as práticas culturais que, em muitas partes do mundo, dão prioridade à nutrição de meninos em detrimento da de meninas. Isto também inclui o fornecimento dos serviços relevantes de saúde, problema que 
foi registrado nos Objetivos de Desenvolvimento para o Milênio, por exemplo, visando reduzir a mortalidade perinatal. Vasto investimento social no tratamento de doenças de homens ricos e brancos também é uma forma de injustiça institucional - mas sob o neoliberalismo, homens ricos e brancos conseguem esta atenção porque podem pagar pelo referido tratamento.

Justiça em relação à inclusão social não é simplesmente uma questão de equilibrar a distribuição dos recursos materiais ou afirmar a igualdade de direitos. Pessoas incluídas socialmente não têm as mesmas necessidades o tempo todo. Consideremos, por exemplo, as necessidades de uma criança em crescimento, uma trabalhadora rural grávida, um mineiro e um idoso desempregado. Nesse âmbito, por um lado, a justiça requer uma calibragem das relações entre instituições e interações, e por outro, as necessidades e desejos destes indivíduos incluídos. Esta calibragem tem de ser um processo social. Ao invés da simples igualdade, precisamos de outro critério de justiça. Talvez o mais relevante, neste âmbito, seja a democratização das instituições envolvidas. Trazer a assistência médica para a esfera pública, para fora de um mercado controlado por homens brancos e ricos é um exemplo.

Discussões sobre justiça facilmente caem numa espécie de negatividade, pois muita energia é invariavelmente empregada para documentar desigualdades e articular reivindicações de reparação. No entanto, realizar tais reivindicações é apenas parte do processo de apreensão da justiça. Em grande medida, a compreensão da justiça é uma questão de mudança nas instituições e nas estruturas sociais materializadas em instituições. Alcançar essas mudanças requer ação coletiva.

Estas são concepções logicamente necessárias, pois quando verificamos caso por caso, através das instâncias da injustiça de gênero mencionadas acima, é evidente que tal reparação trata-se de um processo inerentemente social que envolve re-construção institucional e cultural. Este cenário é familiar às mudanças sociais pós-conflito e pós-ditadura; na África do Sul, após a Apartheid, este panorama foi denominado como "transformação", embora centrado sobre as desigualdades raciais. Uma transformação social em termos de gênero se faz necessária para que se possam efetuar distribuições 
de recursos mais igualitárias, reconhecimento mais adequado, proporcionar melhorias de vida em prol da inclusão social e um maior desenvolvimento de relações respeitosas com a terra.

Uma agenda internacional de "direitos humanos" tornou-se extremamente influente entre as organizações feministas, gays e lésbicas e, recentemente, foi adotada como um dos principais modelos para as políticas transgêneros (Conselho Internacional de Direitos Humanos de 2009; Currah; Juang e Minter 2006). Este é um fato compreensível em uma era neoliberal, quando os movimentos sociais tendem a ser substituídas por ONGs, e uma abordagem dos "direitos" tem sido relevante nas organizações transnacionais. Todavia, o argumento supracitado oferece apenas uma versão frágil da luta pela justiça de gênero. A agenda de direitos formais loca a legalidade do profissional e a tomada de decisão judicial no cerne da questão, onde um envolvimento massivo e um desenvolvimento institucional precisam estar. E as preocupações a respeito de identidades marginalizadas são uma forma muito limitada de compreender a injustiça de gênero. Precisamos de uma compreensão social muito mais vigorosa a esse respeito.

\section{PERSPECTIVAS SOCIAIS SOBRE GÊNERO}

Inúmeras pesquisas de gênero se baseiam em uma abordagem categórica, fundamentalmente estática. Nesta forma de abordagem, a questão do "gênero" envolve duas categorias, masculino e feminino. A diferença natural é presumida; neste tipo de abordagem, falar de gênero é falar da diferença entre essas duas categorias. Praticamente todas as pesquisas quantitativas sobre gênero, incluindo pesquisas de cunho político, tomam tal abordagem. A pesquisa biomédica geralmente vê o gênero simplesmente como uma questão de diferença reprodutiva biológica (embora atualmente isto seja contestado na sociologia da saúde: ver Kuhlmann e Annandale, 2010). O Categorialismo existe também nas ciências sociais, na forma da teoria do "papel sexual", na qual duas categorias distintas são compreendidas em termos de normas sociais binárias. 
Alguns trabalhos de cunho político sobre o gênero também se baseiam em concepções unitárias. Tais formas de compreensão foram historicamente necessárias para o estabelecimento da voz das mulheres nas arenas políticas dominadas pelos pressupostos e práticas patriarcais. Mas a ênfase na solidariedade das mulheres tem frequentemente levado a um tratamento destas como uma simples categoria indiferenciada. Não é de surpreender que alguns movimentos tenham concebido também os homens e a masculinidade em termos essencialistas.

Inúmeras forças afastaram a compreensão do gênero de uma perspectiva biológico-dicotômica. Estudos sobre a sexualidade têm crescido, fortemente influenciados pela urgência da luta contra a pandemia do HIV-AIDS, e a diversidade e a complexidade da prática sexual se tornaram claras. Questões envolvendo relações sociais no domínio do gênero tornaram-se inevitáveis. A escala chocante de violência de gênero em todo o mundo tornou-se evidente, incluindo não só a violência doméstica e o estupro civil, mas também assassinatos e estupros na guerra, além da "limpeza social" violenta contra os homens e mulheres homossexuais e travestis. Padrões de gênero no trabalho, no desemprego e no controle da terra e da riqueza foram reconhecidos como questões importantes - mudando sob a globalização neoliberal. A inclusão social de gênero tornou-se uma questão relativa a métodos contraceptivos, "mudança de sexo" e recursos da bio-tecnologia como a IVF (fertilização in vitro), que incita problemas. E na época das guerras americanas no Iraque e no Afeganistão, a relação entre o Norte e o Sul globais tornou-se novamente uma questão de gênero, especificamente sobre dominação cultural e democracia de gênero.

Nenhum desses problemas pode ser tratado a partir de simples modelos dicotômicos acerca do gênero, nos quais as mulheres estão todas numa caixa separada e os homens todos, noutra. Também tem havido um crescente reconhecimento da diversidade de vozes e experiências dentro dos movimentos femininos. Este tem sido o tema de vários conflitos ao longo das últimas três décadas, abarcando as práticas da maioria dos movimentos feministas em todo o mundo, que evoluem para alcançar maior pluralidade e inclusão. 
Somando-se a complexidade da questão está o crescimento de pesquisas sobre homens e masculinidades, um campo em que o Sul - incluindo o Brasil, Chile, Austrália e África do Sul - tem se mantido ativo (Arilha et al., 1998; Olavarria, 2009; Connell, 2005; Morrell, 2001a). Estudos acerca das sexualidades masculinas, a diferenciação das masculinidades e os padrões das relações de gênero entre homens esclarecem a análise moderna de gênero. Não apenas isso, pesquisas sociais sobre masculinidades e as comunidades em que os homens são formados têm cada vez mais permitido que se compreenda a ação social a respeito da reforma de gênero, em uma escala internacional (Lang et al., 2008).

A pesquisadora feminista alemã Carol Hagemann-White (2001) sumarizou toda a discussão quando disse: "Gênero é uma relação". Uma vez que reconheçamos que os problemas críticos são sobre essa (extremamente complexa) relação, não podemos retornar ao categorialismo, a imagem das duas caixas do gênero; nem para o tipo de discurso político no qual "gênero" é simplesmente um sinônimo para "mulheres".

Precisamos de uma forma de análise social do gênero. Mas quais conceitos científico-sociais devemos utilizar para refletir sobre gênero e sexualidade, conceitos que seriam adequados para os problemas já mencionados e também para as questões políticas e práticas que derivam deles?

Neste ponto, o trabalho inicial de Heleieth Saffioti representa um grande avanço. Partindo do marxismo europeu, A Mulher na Sociedade de Classes (1969) ofereceu considerações acerca do gênero que se distinguem de três maneiras. Primeiro, Saffioti trata mulheres e homens de forma sistemática, como representantes de uma estrutura de relações sociais. Em segundo lugar, ao contrário do feminismo marxista dominante no Norte global da época, a autora radicalmente historiciza tal estrutura, tratando-a em termos de um desenvolvimento através do tempo. Em terceiro lugar, Saffioti reconheceu a especificidade da questão do colonialismo na formação de relações de gênero e sexualidade.

As soluções originais de Saffioti para problemas conceituais não são necessariamente aquelas que seguiríamos hoje; a autora es- 
tava, na época, comprometida com uma concepção marxista do capitalismo e da luta de classes como determinantes irrevogáveis. Mas Saffioti estava absolutamente correta em tentar desenvolver uma abordagem em larga escala das relações de gênero. Nós ainda precisamos de ferramentas conceituais para a compreensão do padrão geral das relações de gênero no nível social.

Na minha própria produção teórica, trato essa questão como "ordem de gênero" de uma dada sociedade, entendida como tendo múltiplas dimensões, incluindo poder, produção e catexia (Connell; 1987). Esta é uma forma de nomear a organização em larga escala das relações de gênero, nas quais a educação dos filhos, o discurso, a violência, as instituições, as emoções e a economia estão interligadas. Apenas a partir de conceitos com esse é que começamos a compreender o que acontece com o gênero sob a perspectiva da colonização, o que está envolvido nas transições pós-coloniais e como as relações de gênero entram em crise em situações de guerra, epidemia, ou re-estruturação econômica.

Isto não significa que o modelo estrutural de gênero deveria ser o mesmo em todos os lugares. Gostaria agora de criticar a minha própria produção teórica anterior a partir de tal fundamentação. Estruturas de gênero são historicamente produzidas e não há razão para pensar que não tenham tomado caminhos diferentes em diferentes partes do mundo.

A análise de Uma Chakravarti's (2003) do sistema de castas na Índia fornece um exemplo eficaz. A autora analisa-o como uma hierarquia de grupos endogâmicos, onde a identidade e o prestígio da casta são mantidos por práticas de castidade, especialmente entre as mulheres. Aqui, o controle extremamente cerrado da sexualidade feminina, no contexto do casamento endogâmico, torna-se uma característica central da ordem de gênero e da ordem social como um todo. Uma estrutura distinta das relações de gênero é produzida, assim como sua própria história, e suas ativas e por vezes violentas políticas contemporâneas.

Em outras partes do mundo colonizado, divisões de raça e um histórico de trabalho escravo moldaram as relações de gênero. Por 
exemplo, as relações de gênero no Brasil moderno são flexionadas pela história da escravidão Africana, pobreza, mobilização e luta das etnias Negras (Nascimento, 2007). Hierarquias relacionadas com a raça entre as mulheres afetam a mobilização política feminista e as formas de solidariedade. O mesmo pode ser dito sobre a colônia de povoamento da Austrália, onde as mulheres Aborígines sentiram-se excluídas das políticas feministas brancas (Moreton-Robinson, 2000).

Uma estruturação em larga escala das relações de gênero é importante. No entanto, não devemos cair em um modelo de sistemas de gênero, onde a estrutura, a ordem normativa ou a hierarquia incorporada a tudo subjugam, e práticas de gênero são reduzidas a repetições intermináveis, citações, ou emanações do habitus. (Este é o problema com a sociologia de Bourdieu, e também com boa parte da discussão pós-estruturalista a respeito da performatividade.) As estruturas de gênero realmente mudam historicamente, existem momentos de crise e de transformação estrutural. Ora isso se dá de maneira dramática e socialmente dolorosa, ora num ritmo mais lento.

Portanto, precisamos de um conceito sociológico de ação, que opere num lugar central da teoria de gênero. Mas na teoria nortenha, esta ação é geralmente entendida como individual. A relação entre ação e estrutura estão se torna uma antinomia irresolúvel do macro vs micro - o que é um beco sem saída característico de textos sociológicos nortenhos. A "ação" frequentemente não se torna mais do que a capacidade dos indivíduos de mudar sua posição em uma estrutura a qual não conseguem mudar fundamentalmente.

As análises advindas do Sul global transcendem essa antinomia de duas formas. Em primeiro lugar, enfatizam a ação coletiva de grupos e movimentos sociais. Precisamos atentar à dinâmica da ação coletiva e institucional, aos encontros e negociações entre grupos, a turbulência e as possibilidades históricas abertas pela sobreposição de coletividades e compromissos.

Em segundo lugar, a análise do Sul global, embasada na experiência histórica de transformações sociais coloniais, lutas anticoloniais e tarefas complexas envolvendo a criação de sociedades pós-coloniais, tende a ver a prática social como ontoformativa. Isto 
é, compreende tal prática na forma de uma capacidade para a criação da realidade social, ou para a transformação das estruturas sociais através de um caráter histórico-temporal.

Insistir que o gênero possui caráter histórico não é o mesmo que dizer que a questão independe de corpos. Um dos pontos fracos da teoria de gênero do Norte é sua dimensão, que adotou a divisão da cultura popular entre a biologia fixa e uma cultura em movimento. Na teoria do "papel sexual" a dicotomia do corpo se dá na forma de uma interpretação social por meio de funções normativas; na teoria queer os modelos normativos sobrepujam o corpo; no discurso biomédico a dicotomia corporal subjulga a cultura e está imediatamente expressa na prática social.

Sobre esta questão, sociologias do corpo, em combinação com os feminismos sulistas, podem decisivamente aprimorar a análise de gênero. Feminismos africanos, através de toda a sua diversidade, têm fortemente enfatizado a questão da maternidade em relação à compreensão do lugar social das mulheres, incluindo também a sua força social (Ampofo; Beoku-Betts; Njambi e Osirim, 2004; 2005; Cornwall; Mama, 2005).

Em tal perspectiva, a biologia não fica de fora ou antecede o costume social; nem o costume oprime os corpos. Há um entrelaçamento, no qual as práticas sociais abordam processos e possibilidades biológicas, e eventos biológicos tomam forma a partir de um dado contexto social. Isto se compara a conceitos emergentes de inclusão social na pesquisa científico-social sobre impotência, biotecnologia, epidemia de HIV, inclusão na juventude, entre outros (por ex. Meekosha, 2011). De fato, o gênero pode ser visto fundamentalmente como uma questão de inclusão a nível social, como um processo que historiciza corpos reprodutivos (Connell e Pearse, 2014).

Isto é o que há de específico acerca do gênero como uma estrutura social. Questões acerca da natalidade e da infância são também relevantes para a análise de gênero, embora surpreendentemente ausentes em diversos textos sobre a performatividade de gênero e suas políticas. As crianças são parte do argumento a respeito da importância das coletividades, porque as práticas sociais que envolvem 
o ato de cuidar da criança, a divisão do trabalho nesta tarefa, assim como práticas coletivas em torno da criação dos filhos estão entre as características definidoras das ordens de gênero.

Abordagens sócio-científicas acerca do gênero e da sexualidade não têm razão alguma para temer a biologia. Quando biólogos interpretam seus próprios dados de forma equivocada, de forma substitutiva para a análise social (o que é comum em relatos da mídia sobre "sexo cerebral", " hormônios ", etc.), então a cura mais eficiente se apresenta nas ciências sociais. Todos os resultados reais da biologia a respeito da reprodução e do crescimento humano são fontes de informação para as ciências sociais, auxiliando na compreensão do vasto processo social da construção e transformação das ordens de gênero. De forma recíproca, a análise social de gênero é extremamente importante para campos práticos de estudo, como no caso da assistência médica, que encontra dificuldades quando o gênero é irrealisticamente reduzido a uma simples dicotomia biológica (Connell, 2012).

\section{A NECESSIDADE DE PERSPECTIVAS SULISTAS NA ANÁ- LISE DE GÊNERO}

Percebi inicialmente que a concepção internacional a respeito do gênero é fortemente moldada pela teoria, metodologia e agendas que vêm do Norte global. Esta é a situação comum de quase todos os campos do conhecimento organizado. Há uma economia global de conhecimento que se assemelha a economia de commodities e finanças, que talvez seja ainda mais hegemonizada pela Europa Ocidental e pela América do Norte.

Nos últimos anos, a recorrente economia do conhecimento tem sido cada vez mais contestada por estudiosos que atentam à questão, não apenas à diferença cultural, mas às desigualdades mundiais evolvendo índices de riqueza e poder, histórias traumáticas de colonialismo e globalização neoliberal e suas consequências na esfera do conhecimento. Tais contestações incluem pesquisas sobre as teorias advindas do Sul (Connell, 2007), tradições alternativas em ciências sociais (Alatas 2006), sociologia pós-colonial (Reuter e Vila, 2010), 
o pensamento descolonial (Quijano, 2000) e mais: o que Rosa (2014) chama de um movimento emergente nas ciências sociais.

$\mathrm{Na}$ acepção desta linha crítica, podemos perceber que as perspectivas originadas no Sul global são fundamentais para o futuro do conhecimento - incluindo as ciências sociais. Isto se aplica à análise de gênero assim como a outros campos. Reconhece-se cada vez mais a necessidade de perspectivas sulistas relativas às questões de gênero (Arango e Puyana de 2007; Viera, 2011; Connell, 2014). A filósofa Maria Lugones (2007), influenciada pelo trabalho de Quijano, propôs o conceito de "colonialidade do gênero". O tratamento dado ao tema pela autora é esquemático, mas a ideia é relevante e marca uma mudança no campo.

Como o reconhecimento da colonialidade do gênero leva a diferentes concepções daquelas que nos são familiares no pensamento feminista nortenho? Existem múltiplas formas. Elucidarei três delas de maneira breve: a compreensão da voz e da identidade; a compreensão do poder e da violência; o reconhecimento da importância da terra.

A voz é o tema central do livro da ativista chilena Julieta Kirkwood, Ser Política en Chile (1986), o qual traça uma narrativa das políticas das mulheres no Chile do século XX. O estabelecimento de uma voz é também uma preocupação central da política feminista no mundo árabe, se considerarmos Nawal El Saadawi (1997). Na Indonésia (Robinson 2009), a questão da voz tem sido o centro de uma longa e turbulenta luta, de grandes proporções e com muitas vicissitudes. Estabelecer uma voz política para as mulheres é também obviamente um problema nas áreas metropolitanas. Embora no mundo colonial e pós-colonial a questão tenha sido moldada justamente pelas relações com as metrópoles, lutas pela independência política, igualdade para os povos colonizados e o problema contínuo da dependência econômica.

Kirkwood deixa claro que o estabelecimento de uma presença política, seu fluxo e refluxo, estava fortemente atrelado a uma cultura pós-colonial, e as formas pelas quais se modificou a formação socioeconômica do Chile foram articuladas a partir de uma ordem econômica e política mundiais. Outra teórica chilena, Sonia Mon- 
tecino (2001), argumenta que a recorrente concepção latino-americana de classes identitárias formadas a partir de confrontos sociais se aplica também as identidades de gênero. Numa análise complexa acerca de variações identitárias, Montecino sugere a ocorrência recente de duas formas distintas de luta política das mulheres, a maternalista e a feminista. As identidades resultantes desta divisão estão conectadas às mudanças na situação econômica das mulheres, de trabalhadoras domésticas não assalariadas a trabalhadoras industriais assalariadas, o que inclui ainda transformações culturais num contexto onde religião e costumes patriarcais moldam fortemente as mulheres dentro de padrões maternais, quer possuam ou não um emprego remunerado.

A ênfase de Montecino na definição coletiva de identidades, de luta social, é marcadamente diferente da concepção usual de "identidade" na teoria de gênero nortenha, basicamente individualista. Os processos aos quais a autora, assim como Kirkwood, se refere não são facilmente compreendidos por um individualismo metodológico, ou por uma perspectiva que trate a consciência ou a identidade como aspectos individuais. Além disso, estas perspectivas são historicamente dinâmicas. As questões de gênero não envolvem um diálogo atemporal entre o biológico e o simbólico. Ao contrário, abarcam vastos processos formativos da história, ao mesmo tempo criativos e violentos (pode-se chamar estes processos de ontoformativos, em vez de performativos), nos quais corpos e culturas estão igualmente em jogo e são constantemente transformados, por vezes, destruídos.

O segundo ponto deriva do reconhecimento da importância da colonização na história mundial. O poder e o Estado trabalham de formas diferentes na periferia se comparados à maneira como funcionam na metrópole.

A colonização em si foi um ato de gênero, realizada por forças de trabalho imperiais, esmagadoramente varoas, provenientes de ocupações masculinizadas que empregaram forças militares e comércio de longa distância. $\mathrm{O}$ estupro de mulheres das sociedades colonizadas era uma etapa normal da conquista. A brutalidade foi levada às sociedades coloniais, fossem colônias de povoamento ou de exploração. A 
re-estruturação das ordens de gênero nas sociedades colonizadas era também uma fase comum no estabelecimento das suas economias, por exemplo, relacionada a incorporação de homens nas economias imperiais como escravos, trabalhadores servis ou trabalhadores emigrantes em plantações e minas. Acrescenta-se ainda a incorporação de mulheres no trabalho doméstico, como trabalhadoras no campo e nas fábricas e, oportunamente, como consumidoras e donas de casa (Mies, 1986) - assim temos uma noção do enorme impacto do poder colonial na história mundial das relações de gênero.

Isto não ocorreu, contudo, casual ou mecanicamente. Foi necessário um esforço cultural e organizacional por parte dos colonizadores, assim como respostas ativas por parte dos colonizados. Nesse esforço, como Ashis Nandy (1983) indicou no caso da Índia, a masculinidade dos colonizadores, bem como a dos colonizados foi alterada. O processo social de criação de masculinidades capazes de operar a maquinaria do império não foi em nenhum lugar tão clara quanto na história Sul Africana, em especial como mostra o trabalho de Robert Morrell (2001b).

A dimensão de poder do gênero, portanto, possui um histórico diferente no mundo colonizado daquele verificado na metrópole. Compreender o Estado como um ator nas políticas sexuais é uma tarefa distinta, quando o interesse do Estado é uma colônia, ou uma póscolônia dependente, ou um Estado em desenvolvimento que segue a estratégia da CEPAL para a industrialização, ou um Estado periférico buscando vantagens competitivas nos mercados mundiais neoliberais.

Finalmente, a justiça e a injustiça de gênero relacionam-se também com questões acerca da terra. A conquista da terra era um ato fundamental na colonização; conforme ilustrado de forma espetacular pelo caso da Austrália, onde um continente inteiro foi apropriado por uma potência colonizadora. Os direitos sobre a terra e a propriedade dispare da terra continuam a ser uma característica fundamental da desigualdade global (Davy, 2009). Inevitavelmente, há uma dimensão de gênero neste problema, incluindo não apenas a dimensão de gênero na expropriação colonial da terra, a reafirmação do direito à terra e os fatos contemporâneos sobre os sem-terra. 
As questões de gênero também se referem à própria problemática da terra. Por exemplo, os movimentos indígenas dos países andinos contemporâneos produziram uma celebração relativa à Pachamama, a Terra, que é a fonte da vida e a portadora dos verdadeiros direitos; isto se tornou parte do repertório dos movimentos de justiça ambiental. Embora de uma forma diferente, o gênero é também uma característica fundamental das relações das sociedades indígenas australianas com a terra (Langton, 1997).

Não precisamos cair no essencialismo para reconhecer que há uma dimensão de gênero na destruição do meio ambiente. Basta que observemos o papel da gestão corporativa masculinizada, forças de trabalho masculinizadas e políticas desenvolvimentistas nos ataques ao meio ambiente. Justiça ambiental e direitos à terra são parte do campo de abrangência da análise social de gênero.

Esta questão é muito bem ilustrada na obra de Bina Agarwal. Em seu magnífico livro A Field of One's Own: Gender and Land Rights in South Asia (Agarwal, 1994), assim como em trabalhos posteriores, Agarwal mostra como as relações de gênero operam em sociedades agrícolas - onde cerca de metade da população mundial, e a maioria das pessoas pobres do mundo, vive. A síntese apresentada pela autora abarca divisões de gênero no trabalho, pobreza, negociações familiares sobre matrimônio, processos políticos locais, normas patriarcais e sua contestação, network e ativismo entre as mulheres, estratégias estatais e evolução das tecnologias na agricultura e silvicultura. Esta é, talvez, a mais completa demonstração contemporânea do caráter dinâmico e multidimensional das relações de gênero. Embora baseada em pesquisas fechadas em comunidades do sul da Ásia, a abordagem de Agarwal pode ser facilmente adaptada para outras regiões. Seu trabalho fornece uma poderosa demonstração da importância dos direitos à terra para a mudança nas relações de gênero. $\mathrm{O}$ estudo mostra como uma mudança de ação pode gerar consequências de grande repercussão para a teoria de gênero e para a estratégia feminista.

Se minhas observações sobre estas três questões estão amplamente corretas, é porque não há uma única ordem de gênero “do 
Sul". Certamente não há - mesmo antes ou depois da colonização. De fato, o reconhecimento da diversidade das ordens de gênero é uma consequência importante dos argumentos das feministas sulistas em fóruns como as Conferências mundiais da ONU sobre as mulheres, da Cidade do México, em 1975, a Pequim, em 1995. O fato de que existem diferenças irredutíveis entre as perspectivas feministas tem sido gradualmente aceito. Porém, é possível manter um diálogo entre essas divisões, como mostrou a socióloga feminista australiana Chilla Bulbeck (1998). Não apenas a questão do diálogo, mas a cooperação política ativa através das fronteiras nacionais, assim como concepções do feminismo numa escala global são elementos cada vez mais evidentes nas políticas de gênero (Naples e Desai, 2002). Chandra Talpade Mohanty (2003) sumariza tais abordagens de forma eficiente na ideia de "feminismo sem fronteiras".

Os feminismos sulistas e as análises de gênero advindas do Sul global alocam a questão da "diversidade", da multiplicidade das formas de gênero, não no nível do individual, mas sim no nível da ordem de gênero e da dinâmica das relações de gênero em uma escala social. A construção das relações Sul-Sul não se refere apenas a uma busca por aquilo que é comum nas histórias de colonização e experiências atuais de subordinação. Esta construção apresentase também como um exame das diferenças na experiência histórica a partir do qual tanto a teoria quanto a prática podem aprender. E quanto mais progredirmos nesses esforços, maiores são as nossas chances de educar o Norte global.

O tipo de conhecimento discutido neste trabalho é uma ferramenta importante para alcançar a justiça de gênero na sociedade em geral. Em fato, é vital para a justiça de gênero em escala mundial. As ciências sociais são uma fração estratégica da autoconsciência da sociedade, necessárias à democracia em escala global, como argumentei em Teoria Sulista (Connell, 2007). O crescimento dos trabalhos autônomos e intelectualmente vívidos sobre o gênero a partir do Sul global é uma contribuição fundamental para este processo. Devemos pensar com ousadia! 


\section{AGRADECIMENTOS}

Sou grata aos colegas e companheiros de seis continentes que me educaram a respeito das questões discutidas neste artigo. Todo trabalho intelectual é coletivo, em certo sentido; trabalhos como este são absolutamente dependentes das contribuições de muitos outros. As ideias neste texto foram originalmente concebidas para um discurso no XVII Congresso da Associação Sociológica Sul Africana, publicado na South African Review of Sociology, 2011, vol. 43 n. 2, 103-115. Agradeço aos organizadores e participantes do congresso e aos editores da Review pelo apoio. Este artigo re-pensa e desenvolve tais ideias, trazendo-as para a luz de trabalhos mais recentes.

\section{REFERÊNCIAS}

AGARWAL, B. A Field of One's Own: Gender and Land Rights in South Asia. Cambridge: Cambridge University Press, 1994.

ALATAS, S. F. Alternative Discourses in Asian Social Science: Responses to Eurocentrism. New Delhi, Sage, 2006.

AMPOFO, A. A.; BEOKU-BETTS, J.; NJAMBI, W. N. \& OSIRIM, M. Women's and gender studies in English-speaking sub-Saharan Africa: A review of research in the social sciences. Gender \& Society, Vol.18, pp.685-714, 2004.

ARANGO, L. G. \& PUYANA, Y. Género, mujeres y saberes en América Latina. Bogotá: Universidad Nacional de Colômbia, 2007.

ARILHA, M.; RIDENTI, S. G. U. \& MEDRADO, B. Homens e Masculinidades: Outras Palavras. São Paulo: ECOS/Editora 34, 1998.

BULBECK, C. Re-orienting Western Feminisms: Women's Diversity in a Postcolonial World. Cambridge: Cambridge University Press, 1998.

CARRERAS, S. N. Sexoservidores - homosexuales - "vestidas" en la ciudad de Puebla. In: RIOS, R. F. M. Sujetos Neoliberales en México. Puebla: Benemerita Universidad Autonoma de Puebla, 2009, pp.17-49.

CARVALHO, M. F. de L.. A (im)possével pureza: medicalização e 
militância na experiência de travestis e transexuais. Sexualidad, Salud y Sociedad: Revista Latinoamericana, no. 8, pp.36-62, 2011.

CHAKRAVARTY, U. Gendering Caste: Through a Feminist Lens. Calcutta: Stree, 2003.

CONNELL, R. Gender and Power: Society, the Person and Sexual Politics. Cambridge: Polity, 1987.

. Scrambling in the ruins of patriarchy: neo-liberalism and men's divided interests in gender change. In: PASERO, U. Gender - from Costs to Benefits. Wiesbaden: Westdeutscher Verlag, 2003, pp.58-69.

. Masculinities. Second edition. Sydney: Allen \& Unwin, 2005. . Northern theory: the political geography of general social theory. Theory and Society, Vol. 35, pp.237-264, 2006.

. Southern Theory: The Global Dynamics of Knowledge in Social Science. Cambridge: Polity, 2007.

. Gender, health and theory: Conceptualizing the issue, in local and world perspective. Social Science \& Medicine, Vol. 74, pp.1675-1683, 2012.

- The sociology of gender in Southern perspective. Current Sociology, Vol. 62, nº 4 , pp.550-567, 2014. DOI: $10.1177 / 0011392114524510$.

CONNELL, R. \& PEARSE, R. Gender: In World Perspective. Third edition. Cambridge, Polity, 2014.

CORNWALL, A. Readings in Gender in Africa. London: International African Institute, James Currey and Indiana University Press, 2005.

CRUZ SIERRA, S. Vida, muerte y resistencia en Ciudad Juárez. Tijuana/ México D. F.: El Colegio de la Frontera Norte/Juan Pablos Editor, 2013.

CURRAH, P.; JUANG, R. M. \& MINTER, S. P. Transgender Rights. Minneapolis: University of Minnesota Press, 2006.

DAS, V. Critical Events: Anthropological Perspective on Contemporary India. New Delhi: Oxford University Press, 1995.

DAVY, B. The poor and the land: poverty, property, planning. Town Planning Review, Vol. 80, nº.3, pp.227-265, 2009. 
ELIAS, J. Hegemonic masculinities, the multinational corporation, and the developmental state: constructing gender in "progressive" firms. Men and Masculinities, Vol.10, n.4, pp.405-421, 2008.

EL SAADAWI, N. The Nawal El Saadawi Reader. London: Zed Books, 1997.

EPSTEIN, D.; MORRELL, R.; MOLETSANE, Relebohile \& UNTERHALTER, Elaine. Gender and HIV/AIDS in Africa south of the Sahara: interventions, activism, identities. Transformation, Vol.54, pp.1-16, 2004.

HAGEMANN-WHITE, C. Was bedeutet "Geschlecht" in der Frauenforschung? Ein Blick zurück und ein Entwurf für heute. In: GÜMEN, U. H. S. \& WEILANDT, S. (Eds.). Zwischen Emanzipationsvision und Gesellschaftskritik: (Re)Konstruktion der Geschlechterordnung in Frauenforschung-FrauenbewegungFrauenpolitik. Münster: Verlag Westfälisches Dampfboot, 2001, pp.63-72.

HARVEY, D. Social Justice and the City. London: Edward Arnold, 1973.

INTERNATIONAL COUNCIL ON HUMAN RIGHTS POLICY. Sexuality and Human Rights. Versoix: ICHRP, 2009.

KIRKWOOD, J. Ser politica en Chile: Las feministas y los partidos. Santiago: FLACSO, 1986.

KUHLMANN, E., \& ANNANDALE, E., (Eds.). The Palgrave Handbook of Gender and Healthcare. Basingstoke: Palgrave Macmillan, 2010.

LANG, J.; GREIG, A. \& CONNELL, R. in collaboration with the Division for the Advancement of Women. The Role of Men and Boys in Achieving Gender Equality. "Women 2000 and Beyond" series. New York: United Nations Division for the Advancement of Women/ Department of Economic and Social Affairs. 2008. At: http.www. un.org/womenwatch/daw/w2000.html.

LANGTON, M. Grandmothers law, company business and succession in changing Aboriginal land tenure systems. In: GALARRWUY, Y. (Ed.). Our Land is Our Life. St. Lucia: University of Queensland Press, 1997, pp.84-116.

LUGONES, M. Heterosexism and the colonial/modern gender system. Hypatia, Vol. 22, nº.01, pp.186-219, 2007.

MAMA, A. Gender studies for Africa's transformation. In: THANDIKA, 
M. (Ed.). African Intellectuals: Rethinking Politics, Language, Gender and Development. Dakar: CODESRIA Books, 2005, pp.94116.

MEEKOSHA, H. Decolonizing disability: thinking and acting globally. Disability and Society, Vol.26, nº6, pp.667-682, 2011.

MIES, M. Patriarchy and Accumulation on a World Scale: Women in the International Division of Labour. London: Zed Books, 1986.

MOHANTY, C. T. Feminism Without Borders: Decolonizing Theory, Practicing Solidarity. Durham: Duke University Press, 2003.

MONTECINO, S. Identidades y diversidades en Chile. In: GARRETÓN, M. A. (Ed.). Cultura y desarollo en Chile. Santiago: Andres Bello, 2001, pp.65-98.

MORETON-ROBINSON, A. Talkin'Up to the White Woman: Indigenous Women and Feminism. St. Lucia: University of Queensland Press, 2000 .

MORGAN, R.; MARAIS, C. \& WELlBELOVED, J. R. (Eds.). Trans: Transgender life stories from South Africa. Auckland Park: Fanele, 2009.

MORRELL, R. (Ed.). Changing Men in Southern Africa. London: Zed Books, 2001a.

MORRELL, R. From Boys to Gentlemen: Settler Masculinity in Colonial Natal, 1880-1920. Pretoria: University of South Africa, 2001b.

NAMASTE, V. Sex Change, Social Change: Reflections on Identity, Institutions, and Imperialism. Second edition. Toronto: Canadian Scholars' Press, 2011.

NANDY, A. The Intimate Enemy: Loss and Recovery of Self under Colonialism. New Delhi: Oxford University Press, 1983.

NAPLES, Nancy \& DESAI, M. (Eds.). Women's Activism and Globalization: Linking Local Struggles and Transnational Politics. New York: Routledge, 2002.

NASCIMENTO, E. L. The Sorcery of Color: Identity, Race, and Gender in Brazil. Philadelphia: Temple University Press, 2007.

OLAVARRÍA, J. (Ed.). Masculinidades y globalización: Trabajo y vida privada, familias y sexualidades. Santiago, Red de Masculinidiad/ es Chile, Universidad Academia de Humanismo Cristiano \& 
CEDEM, 2009.

QUIJANO, A. Coloniality of power and Eurocentrism in Latin America. International Sociology, Vol. 15, nº.02, pp.215-232, 2000.

RATELE, K. Subordinate black South African men without fear. Cahiers d'Études Africaines, Vol. 53 nº. 1-2, pp.247-268, 2013.

RAWLS, J. A Theory of Justice. Cambridge, MA: Harvard University Press, 1971.

REUTER, J. \& VILLA, P.-I. (Eds.). Postkoloniale Soziologie: Empirische Befunde, theoretische Anschlüsse, politische Intervention. Bielefeld: Transcript, 2010.

ROBINSON, K. Gender, Islam and Democracy in Indonesia. London: Routledge, 2009.

ROSA, M. C. Theories of the South: Limits and perspectives of an emergent movement in social science. Current Sociology, Vol.62, n², pp.01$17,2014$.

SAFFIOTI, H. I.. B. A mulher na sociedade de classes: mito e realidade. São Paulo: Quatro Artes, 1969.

. Gênero, patriarcado, violência. São Paulo: Fundação Perseu Abramo, 2004.

VIERA DE JESUS, D. S. Bravos novos mundos: uma leitura pós-colonialista sobre masculinidades ocidentais. Estudos Feministas, Vol. 19, nº. 1, pp.125-139, 2011.

WALZER, M. Spheres of Justice: A Defense of Pluralism and Equality. New York: Basic Books, 1983.

YOUNG, I. M. Justice and the Politics of Difference. Princeton: Princeton University Press, 1990.

Recebido: 17/05/2014.

Aprovado: 11/11/2014. 